Article

\title{
Deterministic Algorithm for Selective Shunt Active Power Compensators According to IEEE Std. 1459
}

\author{
Nicolás Muñoz-Galeano ${ }^{1}$ (D), Salvador Orts-Grau ${ }^{2, *}$ (D), Salvador Seguí-Chilet ${ }^{2}$, \\ Francisco J. Gimeno-Sales ${ }^{2}$ and Jesús M. López-Lezama ${ }^{1}$ \\ 1 Departamento de Ingeniería Eléctrica, Facultad de Ingeniería, Universidad de Antioquia, calle 67 No 53-108, \\ 050010 Medellín, Colombia; nicolas.munoz@udea.edu.co (N.M.-G.); jmaria.lopez@udea.edu.co (J.M.L.-L.) \\ 2 Instituto Interuniversitario de Investigación de Reconocimiento Molecular y Desarrollo Tecnológico, \\ Universitat Politècnica de València, Camino de Vera 14, 46022 Valencia, Spain; ssegui@eln.upv.es (S.S.-C.); \\ fjgimeno@eln.upv.es (F.J.G.-S.) \\ * Correspondance: sorts@eln.upv.es; Tel.: +34-963-877-000 (ext. 76084)
}

Academic Editor: Akhtar Kalam

Received: 27 September 2017; Accepted: 2 November 2017; Published: 7 November 2017

\begin{abstract}
This paper proposes a deterministic algorithm to scale the reference currents of a shunt active power compensator (SAPC) based on IEEE Std. 1459 power decomposition when SAPC maximum output compensating current is going to be exceeded. The selective SAPC is proposed to improve power quality and energy efficiency in power networks by means of the cancelation or reduction of the non-efficient powers $\left(Q_{1}{ }^{+}, S_{U 1}, S_{e N}\right)$. The non-efficient powers can be reduced in six possible sequences according to the priority of compensation. When SAPC maximum output current capacity is exceeded, the proposed algorithm limits the SAPC output compensating currents and the non-efficient currents can only be partially reduced in the power network. The reduction of the non-efficient powers depends on the selected compensation sequence. Experimental results for several compensation sequences demonstrate the appropriate operation of the selective SAPC using the proposed scaling algorithm.
\end{abstract}

Keywords: selective compensation; shunt active power compensator; IEEE Std. 1459 power terms; power quality; non-efficient currents

\section{Introduction}

The existence of non-efficient powers in electrical systems causes increases in line and transformer power losses, lack of stability of the electrical system, voltage asymmetries, distortions in the three-phase power supply, and so on. SAPCs are developed to improve power quality and energy efficiency in the electrical system, providing the load non-efficient currents and avoiding the flow of these currents through the power network. When SAPCs have enough current capacity, non-efficient currents can be completely compensated (global compensation) and the power system operates with the highest power quality standards. Some studies related to the reduction of the non-efficient currents for unbalanced three-phase four-wire systems under non-sinusoidal conditions using the global compensation approach are detailed in [1-7]. In [7] the authors present a bidirectional front-end converter connected between the mains power system and a general purpose DC bus connecting distributed generators and passive loads. The bidirectional power flow with the mains is achieved by means of fundamental component currents.

In the last decade, the interest in the selective compensation of load non-efficient currents has increased, as it is demonstrated by the number of publications dealing with this topic [8-19]. Selective SAPCs contribute to reduce losses in the power networks and at the same time can be used for the dynamic support of the grid following the settings established by the power network managers. 
According to IEEE Std. 1459, the non-efficient currents can be decomposed in fundamental and harmonic current terms. Selective SAPCs usually focus on the harmonic currents cancellation, without considering the non-efficient currents demanded by unbalanced and reactive linear loads. Most of the works dealing with harmonic cancellation concern about fast response and harmonic detection [8-10]. However, they do not focus on the SAPC rating and overloading issues.

SAPC rating is determined by the maximum instantaneous current that can be delivered. In the case of SAPC overloading condition, the non-efficient currents demanded by loads cannot be completely compensated and the SAPC output currents must be limited or the SAPC must be disconnected. The implementation of a selective SAPC permits to choose the SAPC output compensating currents that avoid SAPC overloading. The most common strategy in selective compensation consists in applying the full or nil compensation of the individual non-efficient current terms, depending on SAPC overloading. With this approach, the operation limits of the components used in the SAPC implementation are not completely achieved and the SAPC does not work at its maximum capabilities [14-17].

A current limiter combined with a control algorithm is proposed in [14] to avoid SAPC overload. The control is based on a current hysteresis loop limiter. They ensure that the SAPC is not overloaded by means of limiting the instantaneous active and non-active currents injected to the power network. The power theory used for the compensation only distinguishes between active $(P)$ and reactive power $(Q)$, without recognizing harmonics or unbalances as non-efficient power terms.

A priority resolver and a gain scheduler are proposed in [15] to avoid SAPC overloading. The SAPC control performs the decomposition of the load current in active, reactive, harmonic, and negative-sequence fundamental current components. The SAPC control sets gains to adjust the reference currents; nevertheless, the algorithm used to obtain such gains is not detailed. A fixed priority compensation order is also established in [15], with harmonic currents being the first preference, followed by the negative sequence and the reactive current components. Another drawback is related to the use of a three-phase three-wire SAPC, which cannot compensate zero-sequences currents that could exist in power networks.

A three-phase four-wire SAPC is used in [16] to allow zero-sequences currents compensation. The SAPC control includes a priority resolver and a gain scheduler, but they assign a gain equal to zero when no compensation is selected or a gain equal to 1 for the full compensation of the selected current term. Load current is decomposed into the following current terms: fundamental positive active, fundamental positive reactive, fundamental negative-sequence, zero-sequence, and harmonic reactive. Zero-sequence current and harmonic current terms are included in the same expression not being possible a complete selective compensation following IEEE Std. 1459 power decomposition.

A control algorithm for selective grid harmonics and interharmonics compensation that relies only on the measurement of the voltage at the point of common connection of distributed generation units is presented in [17].

A SAPC optimization algorithm based on linear matrix inequalities (LMIs) is proposed in [18], with a power decomposition that is also based on IEEE Std. 1459. The algorithm is implemented in an experimental three-phase four-wire SAPC prototype. A quadratically-constrained quadratic program is solved by means of LMI formulation, which permits obtaining gains for selective compensation when SAPC is overloaded. The main drawback is that the reference currents are calculated on a PC, not being adequate for rapid changes of load current. Another inconvenience is that the current decomposition is done in rectangular coordinates without identifying the different non-efficient components of the load current. Additionally, it operates with root mean square (RMS) phasors, losing waveform information.

This paper deals with the use of a deterministic algorithm for the selective compensation of the load non-efficient currents that a SAPC can compensate when overloading problems arise. The proposed algorithm extends the work presented in [19] by means of the calculation of the scaling factors that, multiplied by the load non-efficient current terms, permit achieving the SAPC maximum 
capabilities. The SAPC control obtains the SAPC reference compensating currents based on IEEE Std. 1459-2010 [20-22]. These currents are scaled using variable factors, avoiding SAPC overloading and permitting the selective compensation to follow an established compensation sequence. The proposed algorithm is deterministic and is based on the information given by the SAPC reference compensating current waveforms. It permits to use all the current capability of the SAPC, achieving the maximum SAPC compensation. The SAPC operation under global compensation mode or selective compensation mode is performed doing the comparison of the maximum instantaneous SAPC output current with the maximum current permitted in the SAPC output. Maximum current in the SAPC output can be limited by the characteristics of the power switches used in the inverter or the passive components in the SAPC output filter.

This paper is organized as follows. In Section 2, SAPC reference currents for the non-efficient power compensation are detailed, ending with the expression proposed for the selective non-efficient current compensation. In Section 3 the algorithm that adjusts the reference currents when the SAPC is overloaded is described. Section 4 shows the experimental results obtained with a SAPC prototype that validates the proposed algorithm. In Section 5, the paper concludes with a summary of the main achievements obtained in the study.

\section{SAPC Output Currents for Selective Compensation According to IEEE Std. 1459 under Overloading Conditions}

A SAPC is equivalent to a controlled three-phase AC current source, as shown in the block diagram of Figure 1. A current control loop ensures that the currents at the SAPC output, the SAPC compensating currents, are proportional to the reference currents calculated by the SAPC control. The SAPC compensating currents improve the power quality of the electric distribution system upstream the point of common connection $(p c c)$ of load, SAPC, and power network.

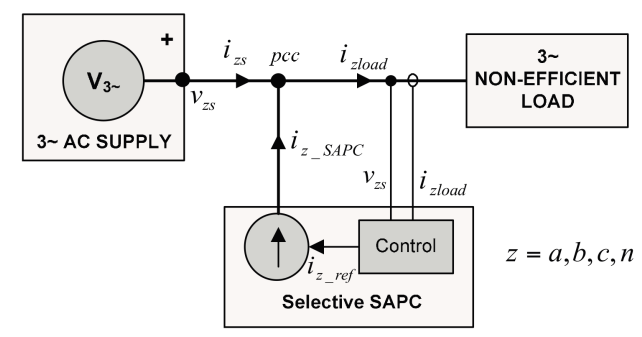

Figure 1. Block diagram showing the connection of a SAPC to the power network at the $p c c$.

The SAPC output currents $\left(i_{z_{-} S A P C}\right)$ are calculated from the measurement of the load currents $\left(i_{z l o a d}\right)$ and the supply voltages $\left(v_{z s}\right)$ at the $p c c(z=a, b, c)$. Global compensation is used when the SAPC has enough capacity to compensate all non-efficient powers detailed in [23]: positive-sequence reactive power $\left(Q_{1}^{+}\right)$, unbalance power $\left(S_{U 1}\right)$, and non-fundamental effective apparent power $\left(S_{e N}\right)$. As indicated in [24], the SAPC output currents for global compensation $\left(i_{z_{-} S A P C_{-} G}\right)$ are calculated as follows:

$$
i_{z_{\_} S A P C_{-} G}=i_{z l o a d}-i_{z 1 \text { load }}^{+a}
$$

where $i_{z 1 l o a d}^{+a}$ are the instantaneous load fundamental positive-sequence active phase currents. These current terms represent the useful currents demanded by the load and are presented in the expression of the fundamental positive-sequence active power $\left(P_{1}^{+}\right)$, the unique power term considered efficient $[23,25]$. The main drawback of a SAPC under overloading condition and using global compensation algorithms is that the SAPC can supply new harmonic components into the power networks, affecting other loads connected in the same distribution system and reducing the power quality indicators. 
Selective compensation mode is used when SAPC output current capacity is exceeded. Under this condition, powers $Q_{1}{ }^{+}, S_{U 1}$, and $S_{e N}$ can only be partially reduced or some are cancelled while others are still present without modification. The approach used to obtain the reference currents of a selective SAPC based on the non-effective power magnitudes defined in IEEE Std. 1459-2010 was presented in [19]. The approach relates each non-efficient power magnitude with some current terms, allowing the selective compensation of the load non-efficient powers. The SAPC output currents that cancel $Q_{1}{ }^{+}$and keep $P_{1}{ }^{+}, S_{U 1}$, and $S_{e N}$ unchanged in the supply lines are as follows:

$$
i_{z Q 1 \_S A P C}=i_{z 1 l o a d}^{+r}
$$

where $i_{z 1 \text { load }}^{+r}$ are the instantaneous load fundamental positive-sequence reactive phase currents and exhibit a phase shift of $90^{\circ}$ with respect to $v_{z 1}{ }^{+}$. The fundamental positive-sequence active voltage in phase $a\left(v_{a 1}{ }^{+}\right)$is the origin of all phase angles. The SAPC output currents that cancel only $S_{U 1}$ are calculated as follows:

$$
i_{z U 1 \_S A P C}=i_{z 1 \text { load }}^{-}+i_{z 1 \text { load }}^{0}
$$

where $i_{z 1 l o a d}^{-}$and $i_{z 1 l o a d}^{0}$ are the instantaneous fundamental negative- and zero-sequence load currents. These fundamental current terms appear due to the connection of linear unbalanced loads in three-phase four-wire power systems. The SAPC output currents that only cancel $S_{e N}$ are obtained as follows:

$$
i_{z H \_S A P C}=i_{z l o a d}-i_{z 1 l o a d}
$$

where $i_{z 1 l o a d}$ are the instantaneous load fundamental currents while $i_{z H \_S A P C}$ only contains the instantaneous non-fundamental currents demanded by non-linear loads. The SAPC output currents that cancel all load non-efficient currents (global compensation mode) can be obtained if Equations (2)-(4) are added up as follows:

$$
i_{z_{-} S A P C_{-} G}=i_{z Q 1 \_S A P C}+i_{z U 1 \_S A P C}+i_{z H_{-} S A P C}
$$

Equations (1) and (5) yield the same result and can be used to compensate the non-efficient currents demanded by the load. When the SAPC output current capacity is exceeded, the SAPC must be disconnected to avoid its failure or the SAPC output currents must be scaled to avoid SAPC overloading. To adjust the SAPC output currents to a value equal or smaller than the SAPC maximum output current $\left(I_{S A P C_{-} \max }\right)$, scaling factors $K_{Q}, K_{U}$, and $K_{H}$ are multiplying in Equation (6) their corresponding current terms. The scaled SAPC output currents $\left(i_{z_{\_} S A P C_{-} K}\right)$ are calculated as follows:

$$
i_{z \_S A P C \_K}=K_{Q} \cdot i_{z Q 1 \_S A P C}+K_{U} \cdot i_{z U 1 \_S A P C}+K_{H} \cdot i_{z H \_S A P C}
$$

The SAPC instantaneous output currents $\left(i_{z_{-} S A P C}\right)$ must not exceed, at any instant, the maximum SAPC output current $\left(I_{S A P C \_m a x}\right)$ to avoid SAPC overloading $\left(I_{S A P C \_m a x} \geq i_{z_{\_} S A P C \_K}\right)$. The subscript " $K$ " is used to indicate that the SAPC selective mode is used. The algorithm to assign the values of $K_{Q}, K_{U}$, and $K_{H}$ according to the power compensation sequences and SAPC current capacity is explained in the next section.

\section{Calculation of the Scaling Factors in a Selective SAPC}

The full cancellation of the load non-efficient powers can be achieved when the SAPC has enough current capacity $\left(I_{S A P C \_m a x} \geq I_{Z_{\_} S A P C_{-} G_{-} \max }\right)$, therefore $K_{Q}=K_{U}=K_{H}=1$. When the output current limit in the SAPC is reached, the SAPC can only partially reduce the non-efficient powers demanded by the load. The values of $K_{Q}, K_{U}$, and $K_{H}$ depend on the selected power compensation sequence,

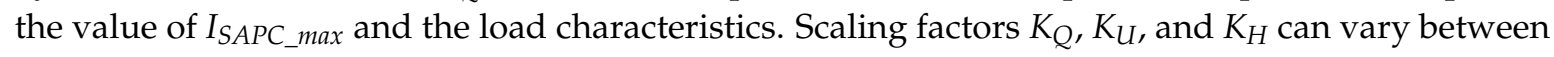


" 0 " (no compensation) and " 1 " (full compensation). The SAPC output effective power, when operating in the selective mode, is calculated as follows:

$$
S_{S A P C}=\sqrt{\left(Q_{1 \_S A P C}^{+}\right)^{2}+\left(S_{U 1 \_S A P C}\right)^{2}+\left(S_{e N_{-} S A P C}\right)^{2}}
$$

There are six possible compensation sequences (CS), attending to the priority given during the compensation to the three main non-efficient power terms $\left(Q_{1}{ }^{+}, S_{U 1}\right.$, and $\left.S_{e N}\right)$ recognized in [23]. The priority in the compensation order can be assigned on the basis of importance of power quality defects, power losses in lines and transformers, engineering economic decisions, and, moreover, considering the interests of consumers and utilities. Table 1 shows the six CS, where $i_{z_{-} \text {comp_ } 1}$ correspond to the compensating current terms with the highest priority, $i_{z_{-} \text {comp } \_2}$ are the second current terms to be compensated, and $i_{z_{-} c o m p \_3}$ correspond to the current terms with the lowest priority. $i_{z_{-} c o m p \_1}, i_{z_{-} c o m p \_2}$, and $i_{z_{-} \text {comp_3 } 3}$ are defined to denote the phase compensating currents without establishing a particular sequence of power compensation between $Q_{1}{ }^{+}, S_{U 1}$, and $S_{e N}$. The corresponding scaling factors are denoted as $K_{1}, K_{2}$, and $K_{3}$, respectively. Scaling factors $K_{1}, K_{2}$, and $K_{3}$ are defined to allow partial compensation of $i_{z_{-} c o m p \_1}, i_{z_{\_} \text {comp } \_2}$, and $i_{z_{-} \text {comp_3 } 3}$ respectively. For example, CS1 indicates that the first power term to compensate is $S_{e N}$, followed by $S_{U 1}$ and $Q_{1}{ }^{+}, Q_{1}{ }^{+}$being the last one to be compensated.

Table 1. SAPC power compensation sequences.

\begin{tabular}{ccccccc}
\hline Compensating Current Priority & CS1 & CS2 & CS3 & CS4 & CS5 & CS6 \\
\hline$i_{z_{\_} c o m p \_1}$ & $S_{e N}$ & $S_{e N}$ & $S_{U 1}$ & $Q_{1}{ }^{+}$ & $S_{U 1}$ & $Q_{1}{ }^{+}$ \\
$i_{z_{\_} \text {comp_2 }}$ & $S_{U 1}$ & $Q_{1}{ }^{+}$ & $S_{e N}$ & $S_{e N}$ & $Q_{1}{ }^{+}$ & $S_{U 1}$ \\
$i_{z_{\_} \text {comp_3 }}$ & $Q_{1}{ }^{+}$ & $S_{U 1}$ & $Q_{1}{ }^{+}$ & $S_{U 1}$ & $S_{e N}$ & $S_{e N}$ \\
\hline
\end{tabular}

With the use of the CS, Equation (6) can be rewritten as follows:

$$
i_{z_{-} S A P C_{-} K}=K_{1} \cdot i_{z_{-} c o m p \_1}+K_{2} \cdot i_{z_{\_} c o m p \_2}+K_{3} \cdot i_{z_{-} c o m p \_3}
$$

If a global compensation mode is used, $i_{z_{-} \text {comp_ } 1}, i_{z_{-} \text {comp_ } 2}$, and $i_{z_{-} \text {comp_3 }}$ are completely compensated and $K_{1}=K_{2}=K_{3}=1$. If a selective compensation mode is needed, three situations arise. These three cases are included as software functions in the flowchart of the main algorithm shown in Figure 2, being denoted as selective compensation modes $\mathrm{SCM}_{1}, \mathrm{SCM}_{1+2}$, and $\mathrm{SCM}_{1+2+3}$, as appears in the first column in Table 2.

The scaling factor of the SAPC output currents must be constant for a complete period of the fundamental current wave to avoid the injection of harmonic current into the power networks. Sub-periodic variable scaling factors cut the waveform and cause new non-fundamental currents in the power network. To avoid an unbalanced compensation, each scaling factor must be unique (the same value for all the phases). Unequal scaling factors asymmetrically modify the reference currents and cause the flow of new unbalanced currents through the power lines.

The algorithm used to adjust the SAPC output currents is mainly divided into three comparisons and four subroutines. The result of the comparisons establishes whether the SAPC is operating in the global compensation mode or in one of the three SCM. Each SCM has its corresponding subroutine, which ends in establishing the adequate scaling factors. The algorithm starts calculating the phase currents defined in Equations (2)-(5) during a complete fundamental period. A true answer in the first comparison means that the global compensation is selected since the SAPC has enough capacity to compensate all non-efficient currents without reaching $I_{S A P C_{-} \max }$, as it is represented in Figure 3. Subroutine "Global Compensation" returns the values $K_{1}=K_{2}=K_{3}=1$ to the algorithm. 


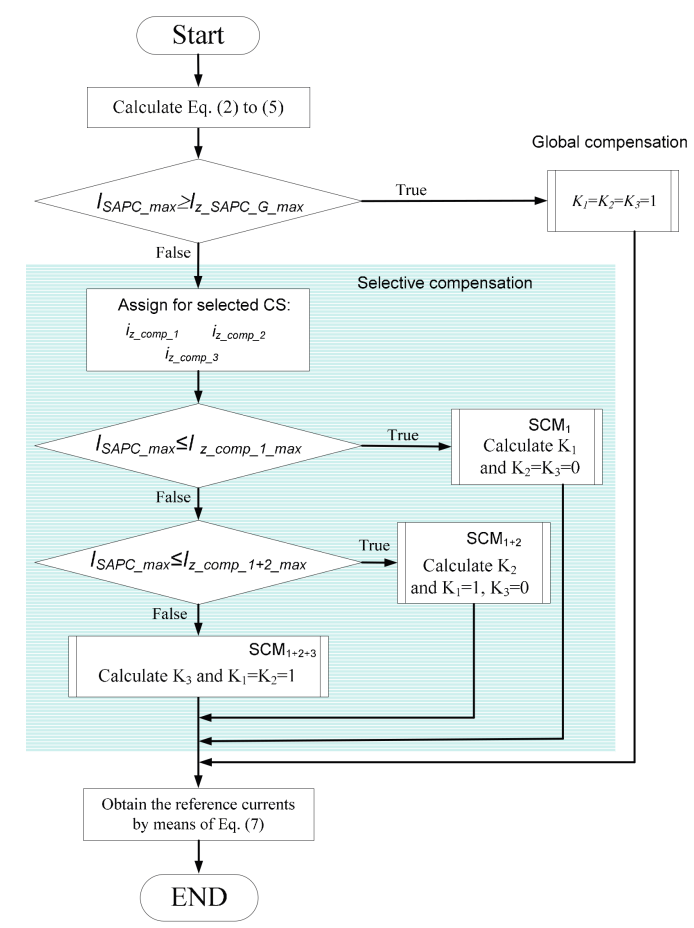

Figure 2. Flowchart of the main algorithm.

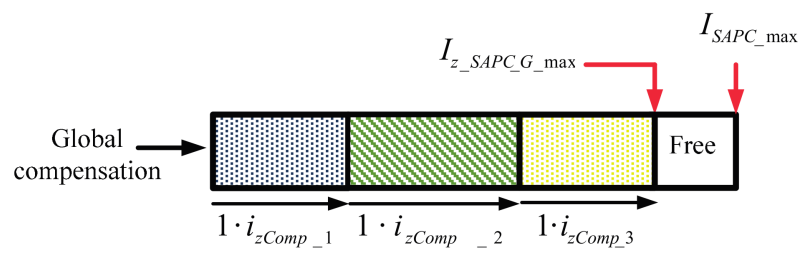

Figure 3. Block diagram of the SAPC limits for the global compensation.

The selective compensation mode is activated when in any phase is verified that $I_{\text {SAPC_max }}<$ $I_{Z_{-} S A P C_{-} G_{-} \max }$ and more comparisons must be done to determine the correct scaling factors. Then, attending to the selected CS, the current terms calculated in Equations (2)-(4) are assigned to the corresponding phase compensating currents $\left(i_{z_{-} \text {comp }}{ }^{*}\right.$, where $\left.{ }^{*}=1,2,3\right)$. The $\mathrm{SCM}_{1}$ subroutine is executed when the maximum value of $i_{z_{-} \text {comp_ } 1}$ is greater than or equal to $I_{S A P C_{-} \max }$ in a complete period of the fundamental current wave. In this case, the full or partial compensation of $i_{z \text { Comp_ } 1}$ must be applied $\left(0<K_{1} \leq 1\right)$, while $i_{z \text { Comp } \_2}$ and $i_{z \text { Comp }} 3$ are not compensated $\left(K_{2}=K_{3}=0\right)$. $\mathrm{SCM}_{1}$ returns the correct value of $K_{1}$ that permits the partial compensation of the non-efficient current with the highest priority considering the CS selected. The subroutine starts calculating the factors $K_{z 1}$ as follows:

$$
K_{z 1}=\frac{I_{S A P C \_m a x}}{I_{z \_c o m p 1 \_\max }}
$$

The minimum value of $K_{a 1}, K_{b 1}$, and $K_{c 1}$ is assigned to $K_{1}$, as appears in the following expression.

$$
K_{1}=\min _{z=a, b, c}\left(\frac{I_{S A P C \_ \text {max }}}{I_{z \_c o m p 1 \_m a x}}\right)
$$

Subroutine $\mathrm{SCM}_{1+2}$ is selected if the SAPC has enough capacity for the complete compensation of $i_{z_{-} \text {comp } \_1}\left(K_{1}=1\right)$, and also has surplus capacity for the partial or complete compensation of $i_{z_{-} \text {comp_ } 2}$ 
$\left(0<K_{2} \leq 1\right)$. For this situation, $i_{z_{-} \text {comp_3 } 3}$ are not compensated $\left(K_{3}=0\right)$, as it is showed in Figure 4 . $\mathrm{SCM}_{1+2}$ starts calculating the time instant $\left(t_{1+2 \_m a x}\right)$ when the sum of $i_{z_{-} \text {comp }} 1$ and $i_{z_{-} \text {comp }} 2$ is maximum $\left(I_{\text {comp__ } 1+2 \_\max }\right)$ and determines which of the three phases is limiting the SAPC operation. For the limiting phase, denoted as \# $\#=\{a, b, c\})$, the values of the currents $i_{\# \_c o m p \_1}$ and $i_{\# \_c o m p \_2}$ are calculated at $t_{1+2 \_ \text {max. }}$ The following relationships are verified:

$$
\begin{aligned}
& i_{\# \_c o m p \_1+2}=i_{\# \_c o m p \_1}+i_{\# \_c o m p \_2} \\
& I_{\text {comp_1 } 1+2 \_\max }=\max \left(i_{\text {\#_comp_1 } 1+2}\left(t_{1+2 \_ \text {max }}\right)\right)
\end{aligned}
$$

For the three phases, the factor $K_{2}$ is calculated as follows:

$$
K_{2}=\frac{I_{S A P C \_\max }-i_{\# \_c o m p \_1}\left(t_{1+2 \_\max }\right)}{i_{\# \_c o m p \_2}\left(t_{1+2 \_ \text {max }}\right)}
$$

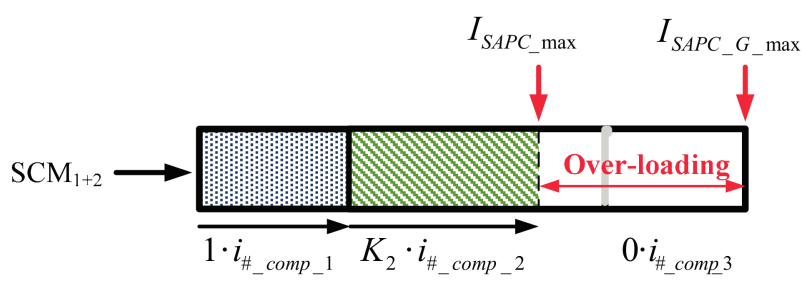

Figure 4. Block diagram of the SAPC limits of operation when SCM1+2 is executed.

Subroutine $\mathrm{SCM}_{1+2+3}$ is executed if the SAPC has enough capacity for the full compensation of $i_{z_{-} \text {comp }} 1$ and $i_{z_{-} \text {comp_2 }}\left(K_{1}=K_{2}=1\right)$, but the remaining SAPC capacity only permits the partial compensation of $i_{z_{-} \text {comp_3 }}\left(0<K_{3}<1\right)$. In this case $I_{\text {comp_1+2_max }}<I_{S A P C \_m a x}<I_{\text {comp_1+2+3_max }}$, where $I_{\text {comp_1+2+3_max }}$ coincides with the maximum of the global compensation current $I_{S A P C_{-} G_{-} \max }$. The subroutine calculates the time instant $\left(t_{G_{-} \max }\right)$ where $i_{z_{-} S A P C_{-} G}$ is maximum $\left(I_{S A P C_{-} G_{-} \max }\right)$ and determines which of the three phases is limiting the SAPC operation. The values of the currents $i_{\# \_c o m p \_1+2}$ and $i_{\# \_c o m p \_3}$ are calculated for the phase \# that limits the SAPC output current at the instant $t_{G_{-} \max }$, verifying the following expression:

$$
\begin{aligned}
& I_{S A P C \_G \_\max }=i_{\# \_c o m p \_1+2+3}\left(t_{G \_\max }\right) \\
& i_{\# \_c o m p \_1+2+3}\left(t_{G_{-} \max }\right)=i_{\# \_c o m p \_1+2}\left(t_{G \_\max }\right)+i_{\# \_c o m p \_3}\left(t_{G \_\max }\right)
\end{aligned}
$$

The current available for the compensation of $i_{\# \_c o m p \_3}$ is calculated as $I_{S A P C_{-} m a x}$ minus $i_{\# \_c o m p \_1+2}\left(t_{G_{-} \max }\right)$, so the value of the factor $K_{3}$ for the three phases is calculated as follows:

$$
K_{3}=\frac{I_{S A P C \_m a x}-i_{\# \_c o m p \_1+2}\left(t_{z_{-} G \_\max }\right)}{i_{\# \_c o m p \_3}\left(t_{z_{-}} G_{-} \max \right)}
$$

Table 2 summarizes the scaling factor used in (8) to obtain the SAPC reference currents.

Table 2. Scale factor assignment.

\begin{tabular}{cccc}
\hline Operating Mode & $\boldsymbol{i}_{z_{\_} c o m p \_1}$ & $\boldsymbol{i}_{z_{\_} \text {comp } \_} \mathbf{2}$ & $\boldsymbol{i}_{z_{\_} \text {comp } \_3}$ \\
\hline Global Comp. & $K_{1}=1$ & $K_{2}=1$ & $K_{3}=1$ \\
$\mathrm{SCM}_{1}$ & $0<K_{1} \leq 1$ & $K_{2}=0$ & $K_{3}=0$ \\
$\mathrm{SCM}_{1+2}$ & $K_{1}=1$ & $0<K_{2} \leq 1$ & $K_{3}=0$ \\
$\mathrm{SCM}_{1+2+3}$ & $K_{1}=1$ & $K_{2}=1$ & $0<K_{3} \leq 1$ \\
\hline
\end{tabular}




\section{Experimental Results}

A three-phase symmetric and fundamental power supply was applied to a three-phase load that includes linear and non-linear parts. During the tests, the load RMS fundamental line to neutral voltages $\left(V_{a 1}, V_{b 1}\right.$, and $\left.V_{c 1}\right)$ were balanced and approximately equal to $125 \mathrm{~V}$. Table 3 shows the main pcc voltage magnitudes (RMS values) calculated applying IEEE Std. 1459. The supply voltages showed, for all performed tests, a distortion lower than $3 \%$ and a slight imbalance.

Table 3. Main voltage magnitudes at $p c c$ (in volts).

\begin{tabular}{ccc}
\hline \multicolumn{1}{c}{$V_{\boldsymbol{a}}=\mathbf{1 2 5 . 4 6}$} & $V_{\boldsymbol{b}}=\mathbf{1 2 6 . 8 2}$ & $V_{\boldsymbol{c}}=\mathbf{1 2 9 . 2 6}$ \\
\hline$\vec{V}_{a 1}=125.44 \angle 0^{\circ}$ & $\overrightarrow{V_{b 1}}=126.78 \angle-120.35^{\circ}$ & $\overrightarrow{V_{c 1}}=129.23 \angle-239.74^{\circ}$ \\
$\overrightarrow{V_{1}^{+}}=127.15 \angle-0.03^{\circ}$ & $\overrightarrow{V_{1}^{-}}=0.82 \angle-124.38^{\circ}$ & $\overrightarrow{V_{1}^{0}}=1.45 \angle 149.23^{\circ}$ \\
$V_{a H}=2.45$ & $V_{b H}=3.24$ & $V_{c H}=3$ \\
$V_{e}=127.19$ & $V_{e 1}=127.16$ & $V_{e H}=2.92$ \\
$T H D_{V a}=1.95 \%$ & $T H D_{V b}=2.55 \% \quad r H D_{V c}=2.36 \%$ & $T H D_{e V}=2.30 \%$ \\
\hline
\end{tabular}

The load used in the test is implemented using an unbalanced linear load in parallel with a balanced three-phase non-linear load. The balanced per-phase non-linear load is built using a single-phase full-bridge diode rectifier with an $\mathrm{LC}$ filter and a resistive load $(L=5.0 \mathrm{mH}, C=2.2 \mathrm{mF}, R=100 \Omega)$. The unbalanced linear load is connected from phase terminals $(a-b-c)$ to neutral wire $(n)$ and has the following values:

- $\quad Z_{\text {a load }}=R_{\text {a load }}=65.9 \Omega / / L_{\text {a load }}=67.2 \mathrm{mH}$.

- $\quad Z_{b \text { load }}=L_{b \text { load }}=67.2 \mathrm{mH}\left(R_{b \text { load }}=\infty \Omega\right)$.

- $Z_{c \text { load }}=L_{c \text { load }}=69.7 \mathrm{mH}\left(R_{\text {cload }}=\infty \Omega\right)$.

Figure 5 shows the load current waveforms (phases a-b-c and neutral from top to bottom). Table 4 summarizes the main load current magnitudes calculated applying IEEE Std. 1459 to the samples acquired with the oscilloscope.

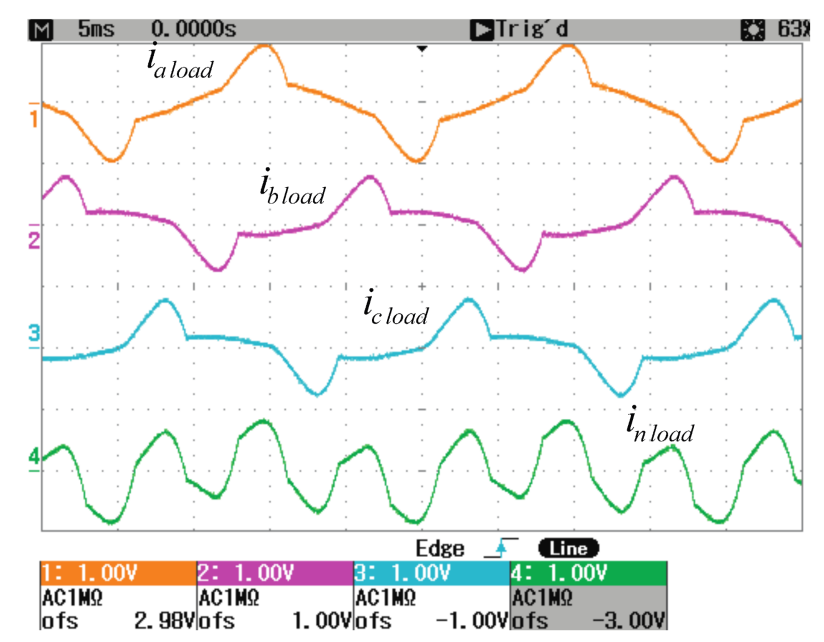

Figure 5. Experimental load currents (network currents before compensation).

A selective SAPC like the one described in references $[21,22,25]$ is placed between the power network and the load, at the $p c c$, as showed in Figure 1. The inverter was built using an intelligent power module (IPM SKiiP 342GD120-314CTV). The SAPC control algorithm was implemented on a TMS320F2812 digital signal processor. The availability of reactive components is the main constraint 
in the construction of the selective SAPC. The SAPC output inductors connected in each phase have $L=6 \mathrm{mH}$ and a maximum RMS current equal to $10 \mathrm{~A}$, limiting the maximum SAPC output apparent power $\left(S_{S A P C \_\max }\right)$ to $3750 \mathrm{VA}$. The $\mathrm{DC}$ bus has a capacitance equal to $7050 \mu \mathrm{F}$ and was designed to handle up to $800 \mathrm{~V}$. Voltage and current sensors used in the experimental SAPC are LEM LV 25-P and LEM LAH 50-P, respectively. Figure 6 shows the implementation of the prototype.

Table 4. Main load current magnitudes (in amps).

\begin{tabular}{|c|c|c|c|}
\hline$I_{a}=4.83$ & $I_{b}=3.54$ & $I_{c}=3.52$ & $I_{n}=4.8$ \\
\hline $\overrightarrow{I_{a 1}}=4.52 \angle-28.62^{\circ}$ & $\overrightarrow{I_{b 1}}=3.14 \angle-166.18^{\circ}$ & $\overrightarrow{I_{c 1}}=3.08 \angle-283.65^{\circ}$ & $\overrightarrow{I_{n 1}}=1.65 \angle-2.59^{\circ}$ \\
\hline \multicolumn{2}{|c|}{$\overrightarrow{I_{1}^{+}}=3.54 \angle-38.07^{\circ} \quad \overrightarrow{I_{1}^{-}}=0.6$} & \multicolumn{2}{|c|}{$-0.45^{\circ} \quad \overrightarrow{I_{1}^{0}}=0.55 \angle 2.59^{\circ}$} \\
\hline \multicolumn{2}{|c|}{$\stackrel{\vec{a}}{I_{z 1 \text { load }}^{+a}}=2.79 \angle 0^{\circ}$} & \multicolumn{2}{|c|}{ 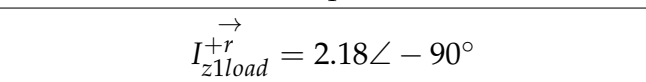 } \\
\hline$I_{a H}=1.7$ & $I_{b H}=1.64$ & $I_{c H}=1.71$ & $I_{n H}=4.51$ \\
\hline$I_{e}=4.01$ & \multicolumn{2}{|c|}{$I_{e 1}=3.64$} & $I_{e H}=1.68$ \\
\hline$T H D_{I a}=37.6 \%$ & $T H D_{I b}=52.2 \%$ & $T H D_{I c}=55.5 \%$ & $T H D_{e I}=46.1 \%$ \\
\hline
\end{tabular}

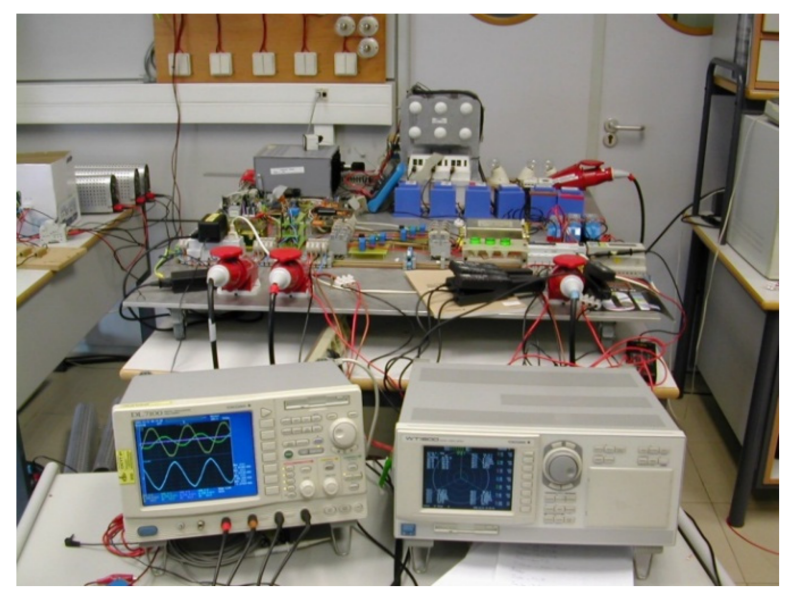

Figure 6. SAPC prototype implemented in the laboratory.

Due to load characteristics disposed for the experimental tests, the $S_{S A P C \_m a x}$ was limited by the DSP controller to $1125 \mathrm{VA}$, so the maximum SAPC output compensating current $\left(I_{S A P C \_m a x}\right)$ is equal to $4.24 \mathrm{~A}$ (equivalent to $3 \mathrm{~A}_{\mathrm{rms}}$ ). For the load used in the tests the maximum currents obtained with Equations (2)-(5) are the following: $I_{z Q 1 \_S A P C \_m a x}=3.08 \mathrm{~A}, I_{z U 1 \_S A P C \_\max }=1.34 \mathrm{~A}, I_{z H_{-} S A P C \_\max }=3.21 \mathrm{~A}$, and $I_{Z_{-} S A P C \_} G_{-} \max =5.56 \mathrm{~A}$. With these values, $\mathrm{SAPC}$ current capacity is reached and the algorithm needs to be executed for adjusting the reference currents.

According to the load and restricted SAPC's capacity, the six CS detailed in Table 1 are evaluated. Table 5 shows the scaling factors for the six CS and the power magnitudes calculated upstream the $p c c$ following the definitions detailed in [23]. The current scaling factors were calculated by the proposed algorithm considering SAPC capabilities. Values included in the second row correspond to the load without the SAPC operation. The following rows show the values obtained with the six CS. $P_{1}{ }^{+}$is increased approximately in $250 \mathrm{~W}$ during SAPC operation because SAPC losses are compensated by means of three balanced fundamental positive-sequence active currents supplied by the power network [19]. The non-efficient currents are full, partial, or not compensated according to the scaling factors determined for each CS. Effective apparent power $\left(S_{e}\right)$ is calculated as follows:

$$
S_{e}=\sqrt{\left(P_{1}^{+}\right)^{2}+\left(Q_{1}^{+}\right)^{2}+\left(S_{U 1}\right)^{2}+\left(S_{e N}\right)^{2}}
$$


Compensation sequence CS4 is the one that produces the minimum $S_{e}$ at the pcc. CS4 has the following scaling factors: $K_{Q}=1, K_{U}=0$, and $K_{H}=0.67$. The application of this scaling factors results in a $Q_{1}{ }^{+}$that is almost reduced to zero $(18.88 \mathrm{VA})$, a $S_{U 1}$ that is not compensated, and a $S_{e N}$ that is partially reduced from $1183.41 \mathrm{VA}$ to $371.71 \mathrm{VA}$. The reduction in $S_{e N}$ is equal to $68.5 \%$, slightly greater than the corresponding scaling factor. This small difference is explained due to minor variations in the $p c c$ characteristics during the measurements that were taken in different moments. The same reason explains the small increase that appears in $S_{U 1}$ when CS4 is applied or in other cases in which the power term is not compensated $(K=0)$ but the power term presents some variation. Information provided in Table 5 proves that the inclusion of the proposed algorithm in the control of a SAPC permits the selective compensation of the non-efficient currents and reduces the non-efficient powers according to the selected compensation sequence.

Table 5. Power magnitudes for load and network for the six CS.

\begin{tabular}{cccccc}
\hline & $\boldsymbol{P}_{\mathbf{1}}{ }^{+}(\mathbf{W})$ & $\boldsymbol{Q}_{\mathbf{1}}{ }^{+}(\mathbf{v a r})$ & $\boldsymbol{S}_{\boldsymbol{U} \mathbf{1}}(\mathrm{VA})$ & $\boldsymbol{S}_{\boldsymbol{e} N}(\mathrm{VA})$ & $S_{\boldsymbol{e}}(\mathrm{VA})$ \\
\hline Load & 1063.49 & 832.09 & 483.76 & 1183.41 & 1859.53 \\
CS1 $(0 ; 0.55 ; 1)$ & 1340.86 & 812.38 & 206.06 & 59.22 & 1582.35 \\
CS2 $(0.4 ; 0 ; 1)$ & 1348.73 & 453.11 & 512.29 & 67.42 & 1513.72 \\
CS3 $(0 ; 1 ; 0.81)$ & 1314.93 & 818.16 & 56.27 & 198.88 & 1562.41 \\
CS4 $(1 ; 0 ; 0.67)$ & 1319.68 & 18.88 & 507.42 & 371.71 & 1462.04 \\
CS5 $(1 ; 1 ; 0.29)$ & 1304.56 & 1.14 & 33.57 & 848.36 & 1556.51 \\
CS6 $(1 ; 1 ; 0.29)$ & 1304.56 & 1.14 & 33.57 & 848.36 & 1556.51 \\
\hline
\end{tabular}

Table 6 shows the per phase SAPC maximum currents $\left(I_{Z_{-} S A P C} \_\right.$max $)$and the apparent power supplied by the SAPC $\left(S_{S A P C}\right)$ for the six CS. Maximum values are used in Table 6 due to the fact that the scaling factor algorithm uses the maximum values of the corresponding signals. It could be considered that the proposed algorithm works appropriately limiting the SAPC currents to the restricted current $(4.24 \mathrm{~A})$ in each phase. $I_{S A P C_{-} \max }$ is slightly overcome in some cases $\left(I_{Z_{-} S A P C_{-} p k}>4.24 \mathrm{~A}\right)$, due to the current ripple in the SAPC output current waveforms (on the order of $0.1 \mathrm{~A}$ ) and the characteristics of the current regulator [22]. The values of $S_{S A P C}$ for the six CS oscillate around 1125 VA. The small deviation around the maximum value established for $S_{S A P C}$ capacity is related with the SAPC control, which works with the non-efficient currents instead of the non-efficient power terms.

Table 6. SAPC maximum current and SAPC output apparent power.

\begin{tabular}{ccccc}
\hline Compensation Sequences & $\boldsymbol{I}_{\boldsymbol{a} \_ \text {max }}(\mathbf{A})$ & $\boldsymbol{I}_{\boldsymbol{b} \_ \text {max }}(\mathbf{A})$ & $\boldsymbol{I}_{\boldsymbol{c} \_ \text {max }}(\mathbf{A})$ & $\boldsymbol{S}_{\text {SAPC }}(\mathrm{VA})$ \\
\hline CS1 & 4.22 & 4.22 & 4.37 & 1158.14 \\
CS2 & 4.22 & 4.37 & 4.22 & 1178.92 \\
CS3 & 4.37 & 4.06 & 4.06 & 1073.42 \\
CS4 & 4.38 & 4.37 & 4.22 & 1149.22 \\
CS5 & 4.22 & 4.39 & 4.37 & 1002.69 \\
CS6 & 4.22 & 4.39 & 4.37 & 1002.69 \\
\hline
\end{tabular}

Table 7 shows the currents in the power network (upstream the $p c c$ ) when SACP control is applying CS4. The benefits obtained with the proposed selective SAPC operation can be seen if the results included in Table 7 are compared with the corresponding values in the load, detailed in Table 4. 
Table 7. Power network current magnitudes when CS4 is applied (in amps).

\begin{tabular}{|c|c|c|c|}
\hline$I_{a s}=4.72$ & $I_{b s}=2.92$ & $I_{c s}=2.87$ & $I_{n s}=2.24$ \\
\hline $\overrightarrow{I_{a 1 s}}=4.69 \angle 3.69^{\circ}$ & $\overrightarrow{I_{b 1 s}}=2.87 \angle-117.22^{\circ}$ & $\overrightarrow{I_{c 1 s}}=2.82 \angle-234.81^{\circ}$ & $\overrightarrow{I_{n 1 s}}=1.74 \angle 1.72^{\circ}$ \\
\hline \multicolumn{2}{|c|}{$\begin{array}{ll}\overrightarrow{I_{1 s}^{+}}=3.46 \angle 3.85^{\circ} & \overrightarrow{I_{1 s}^{-}}=0\end{array}$} & \multicolumn{2}{|c|}{$\angle 4.62^{\circ} \quad \overrightarrow{I_{1 s}^{0}}=0.58 \angle 1.72^{\circ}$} \\
\hline \multicolumn{2}{|c|}{$\overrightarrow{I_{z 1 s}^{+a}}=3.45 \angle 0^{\circ}$} & \multicolumn{2}{|c|}{$\overrightarrow{I_{z 1 s}^{+r}}=0.23 \angle 90^{\circ}$} \\
\hline$I_{a H s}=0.51$ & $I_{b H s}=0.54$ & $I_{c H s}=0.54$ & \multirow{2}{*}{$\begin{aligned} I_{n H s}=1.41 \\
I_{e H s}=0.53\end{aligned}$} \\
\hline$I_{e s}=3.6$ & \multicolumn{2}{|c|}{$I_{e 1 \mathrm{~s}}=3.57$} & \\
\hline$T H D_{\text {Ias }}=10.9 \%$ & $T H D_{I b s}=18.8 \%$ & $T H D_{\text {Ics }}=19.2 \%$ & $T H D_{\text {eIs }}=14.8 \%$ \\
\hline
\end{tabular}

In order to show the algorithm effectiveness, the SAPC output currents and the power network currents for CS4 are shown in Figures 7 and 8, respectively.

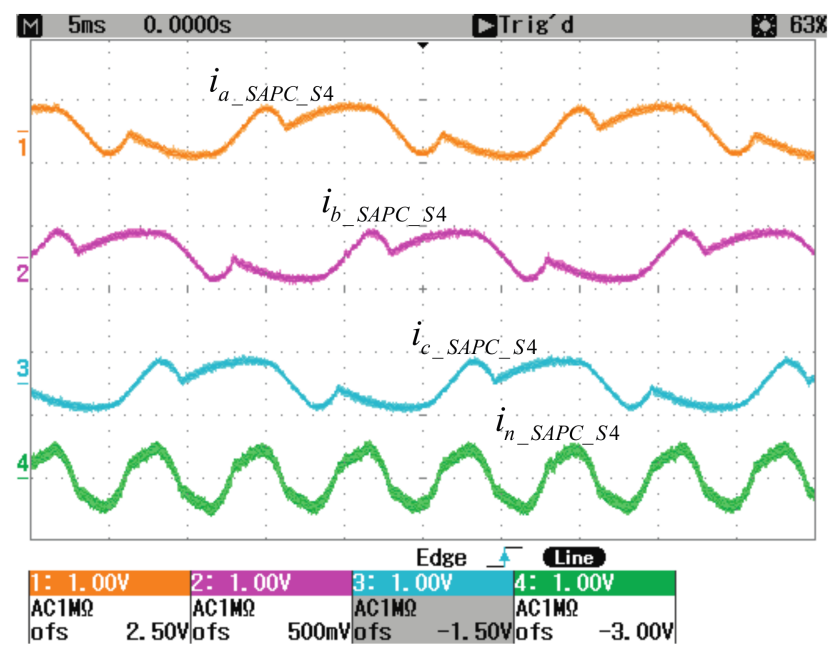

Figure 7. SAPC output currents for the CS4 sequence.

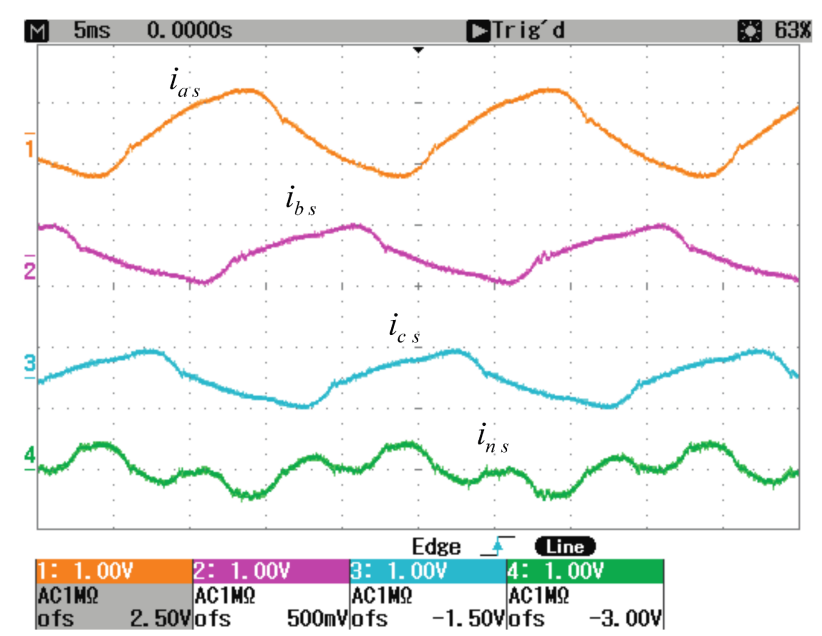

Figure 8. Power network currents after compensation with CS4.

For CS4 the SAPC generates the compensating currents for reducing the reactive and distortion currents demanded by the load $\left(i_{z 1 \_S A P C}^{+r}\right.$ and $\left.i_{z H_{-} S A P C}\right)$. The load current term $i_{z 1 \text { load }}^{+r}$ is completely 
supplied by the SAPC since $K_{Q}=1$, producing the reduction of $I_{z 1 \text { load }}^{+r}$ from 2.18 A to $0.23 \mathrm{~A}$ (a reduction of $89.4 \%$ ). The current $i_{z H_{-} S A P C}$ is partially injected to the $p c c$ since $K_{H}=0.67$, producing the decrease of $I_{e H}$ from $1.68 \mathrm{~A}$ to $0.53 \mathrm{~A}$ (a reduction of $68.4 \%$ ). The current $i_{z U 1} \_$SAPC is not compensated since $K_{U}=0$, as it can be seen in the values of $I_{1}{ }^{-}$and $I_{1}{ }^{\circ}$ that keep similar values as in Table 4 (before compensation) and Table 7 (with CS4 compensation). After compensation, the effective current $I_{e}$ is reduced from $4 \mathrm{~A}$ to $3.6 \mathrm{~A}$. The reduction in the fundamental effective current $I_{e 1}$ due to the cancelation of $i_{z 1 \text { load }}^{+r}$ is small (from 3.64 A to $3.57 \mathrm{~A}$ ) since the other fundamental current terms are still present in the load current $\left(i_{z 1 \text { load }}^{+a}, i_{\text {z1load }}^{-}\right.$and $\left.i_{z 1 \text { load }}^{0}\right)$. The neutral current $\left(I_{n}\right)$ is also reduced from $4.8 \mathrm{~A}$ to $2.2 \mathrm{~A}$ (a reduction of $54 \%$ ) due to the reduction of some zero-sequence harmonic currents that can be seen in bottom plot in Figure 5 (load) and Figure 8 (upstream pcc). The harmonic neutral current $\left(I_{n H}\right)$ decreases by $68.8 \%$, varying from $4.5 \mathrm{~A}$ to $1.4 \mathrm{~A}$ due to $K_{H}=0.67$ for CS4 case. The effect of the SAPC operation is also seen in the $T H D_{i}$ values. Minimum load $T H D_{i}$ is around $37 \%$ while with the CS4 selective SAPC operation and they change to values between $10.9 \%$ and $19.2 \%$. If a higher decrease in the values of $T H D_{i}$ is desired, CS1 or CS2 must be selected, since both prioritize the cancelation of the harmonic current terms while, in CS4, the SAPC only partially reduces these currents. For the sake of shortness, only values of $T H D_{i}$ are given for CS1: $T H D_{I a}=1.99 \%, T H D_{I b}=1.99 \%, T H D_{I c}=2.28 \%$, and $T H D_{e I}=1.99 \%$. These values demonstrate how the selective SAPC can be used to reduce the load $T H D_{i}$ to high power quality levels.

\section{Conclusions}

Based on the analysis of the load instantaneous non-efficient current waveforms, a deterministic algorithm is proposed to avoid the SAPC overloading that appears when load non-efficient currents are greater than the maximum SAPC current capability. The proposed algorithm improves common ON/OFF selective SAPCs in which scaling factors are only 0 or 1 . Load non-efficient currents compensated by the SAPC operation are defined considering the first decomposition proposed in IEEE STD. 1459 for the non-efficient powers, including $Q_{1}{ }^{+}, S_{U 1}$, and $S_{e N}$. Three scaling factors $\left(K_{Q}, K_{U}\right.$, and $K_{H}$ ) are used to reduce the current terms related with $Q_{1}{ }^{+}, S_{U 1}$, and $S_{e N}$. The proposed algorithm permits to obtain the scaling factors that limit the SAPC output currents for the six sequences of current compensation (CS1 to CS6). Each CS gives different priorities to the non-efficient current terms. The values of the scaling factors can vary between 0 and 1 . The final value of the scaling factors is determined considering the selected power compensation sequence, the maximum SAPC output current and the load characteristics.

The experimental results included in the paper for the six CS showed the effectiveness of the proposed algorithm. The corresponding scaling factor for the six CS are calculated by the proposed algorithm and applied to the SAPC control. The main current parameters are measured in the power network and compared with the values required by the load. In all cases, the apparent power supplied by the SAPC is around the value of 1125 VA established as a SAPC limit. Results obtained for CS4 are detailed, including current magnitudes and $T H D_{i}$ upstream the $p c c$. CS4 is selected for being the CS that most reduces the effective power in the power network $\left(S_{e}\right.$ is reduced to $1462.04 \mathrm{VA}$ for CS4). Waveforms and magnitudes of the SAPC output and the power network currents are included, demonstrating the correct behavior of the current controller during the operation of the SAPC in the selective mode. The reduction in the non-efficient currents that are flowing in the power networks during the selective SAPC operation agrees with the priorities established in CS4 and the values calculated for the scaling factors. Selecting the corresponding CS, other quality indices can be improved, as it is demonstrated with the small $T H D_{i}$ values (around $2 \%$ ) obtained when CS1 is selected.

Experimental results demonstrate that the algorithm calculates the scaling factors for any sequence of current compensation. According to the selected CS, the SAPC delivers to the load all, part, or none of the non-efficient current terms. The effectiveness of the algorithm has been experimentally verified for the six CS, showing a direct relationship between the current scaling factor and the compensated non-efficient powers (for CS4 scaling factors are $K_{Q}=1, K_{U}=0$, and $K_{H}=0.67$; this yields to 
the reduction of $Q_{1}{ }^{+}$almost to zero, $S_{U 1}$ is not compensated, and $S_{e N}$ is partially reduced from 1183.41 VA to $371.71 \mathrm{VA}$ ). The inclusion of the deterministic algorithm permits the selective SAPC operation at its maximum capabilities, CS4 most reduces the apparent power in the network and at the same time use adequately the apparent power available $\left(S_{S A P C}=1149.22 \mathrm{VA}\right)$. The proposed algorithm can also be used for other current decompositions: individual harmonics, negative-sequence currents, zero-sequence currents, etc.

Acknowledgments: The authors gratefully acknowledge the Universidad de Antioquia (UdeA) for the support of "Convocatoria Programática 2016, código 2015-7747" and the Ministerio de Economía y Competitividad (Spain) for the support of DPI2011-28606.

Author Contributions: All authors contributed to the paper. Salvador Seguí-Chilet was the director of the research project; Nicolás Muñoz-Galeano was responsible for the programing and developing of the algorithm; Salvador Orts-Grau and Francisco J. Gimeno-Sales were responsible for the development of the prototype; and Jesús M. López-Lezama was the advisor of the project. All authors were responsible for organizing and revising the whole paper and for designing and analyzing all tests and results.

Conflicts of Interest: The authors declare no conflicts of interest.

\section{References}

1. Routimo, M.; Salo, M.; Tuusa, H. Comparison of Voltage-Source and Current-Source Shunt Active Power Filters. IEEE Trans. Power Electron. 2007, 22, 636-643. [CrossRef]

2. Mishra, M.K.; Ghosh, A.; Joshi, A.; Suryawanshi, H.M. A Novel Method of Load Compensation under Unbalanced and Distorted Voltages. IEEE Trans. Power Deliv. 2007, 22, 288-295. [CrossRef]

3. Salmeron, P.; Herrera, R.S. Distorted and Unbalanced Systems Compensation within Instantaneous Reactive Power Framework. IEEE Trans. Power Deliv. 2006, 21, 1655-1662. [CrossRef]

4. Tey, L.H.; So, P.L.; Chu, Y.C. Improvement of Power Quality Using Adaptive Shunt Active Filter. IEEE Trans. Power Deliv. 2005, 20, 1558-1568. [CrossRef]

5. Chen, C.-C.; Hsu, Y.-Y. A novel approach to the design of a shunt active filter for an unbalanced three-phase four-wire system under nonsinusoidal conditions. IEEE Trans. Power Deliv. 2000, 15, 1258-1264. [CrossRef]

6. Shukla, S.; Mishra, S.; Singh, B.; Kumar, S. Implementation of Empirical Mode Decomposition Based Algorithm for Shunt Active Filter. IEEE Trans. Ind. Appl. 2017, 53, 2392-2400. [CrossRef]

7. Brenna, M.; Lazaroiu, G.C.; Superti-Furga, G.; Tironi, E. Bidirectional front end converter for DG with disturbance insensitivity and islanding-detection capability. IEEE Trans. Power Deliv. 2008, 23, 907-914. [CrossRef]

8. Briz, F.; Garcia, P.; Degner, M.W.; Diaz-Reigosa, D.; Guerrero, J.M. Dynamic Behavior of Current Controllers for Selective Harmonic Compensation in Three-Phase Active Power Filters. IEEE Trans. Ind. Appl. 2013, 49, 1411-1420. [CrossRef]

9. Freijedo, F.D.; Doval-Gandoy, J.; Lopez, O.; Fernandez-Comesana, P.; Martinez-Penalver, C. A SignalProcessing Adaptive Algorithm for Selective Current Harmonic Cancellation in Active Power Filters. IEEE Trans. Ind. Electron. 2009, 56, 2829-2840. [CrossRef]

10. Wang, Y.F.; Li, Y.W. Three-Phase Cascaded Delayed Signal Cancellation PLL for Fast Selective Harmonic Detection. IEEE Trans. Ind. Electron. 2013, 60, 1452-1463. [CrossRef]

11. Orts-Grau, S.; Gimeno-Sales, F.J.; Segui-Chilet, S.; Abellan-Garcia, A.; Alcaniz, M.; Masot-Peris, R. Selective Shunt Active Power Compensator Applied in Four-Wire Electrical Systems Based on IEEE Std. 1459. IEEE Trans. Power Deliv. 2008, 23, 2563-2574. [CrossRef]

12. Sawant, R.R.; Chandorkar, M.C. A Multifunctional Four-Leg Grid-Connected Compensator. IEEE Trans. Ind. Appl. 2009, 45, 249-259. [CrossRef]

13. Czarnecki, L.S. Effect of Supply Voltage Harmonics on IRP-Based Switching Compensator Control. IEEE Trans. Power Electron. 2009, 24, 483-488. [CrossRef]

14. Xu, Y.; Li, H.; Rizy, D.T.; Li, F.; Kueck, J.D. Instantaneous active and nonactive power control of distributed energy resources with a current limiter. In Proceedings of the 2010 IEEE Energy Conversion Congress and Exposition, Atlanta, GA, USA, 12-16 September 2010; pp. 3855-3861.

15. Singh, B.; Verma, V. Selective Compensation of Power-Quality Problems through Active Power Filter by Current Decomposition. IEEE Trans. Power Deliv. 2008, 23, 792-799. [CrossRef] 
16. Lu, W.; Xu, C.; Li, C. Selective compensation of power quality problems with a three-phase four-leg shunt active filter. In Proceedings of the 2011 9th World Congress on Intelligent Control and Automation (WCICA), Taipei, Taiwan, 21-25 June 2011; pp. 166-171.

17. D'Arco, S.; Ochoa-Gimenez, M.; Piegari, L.; Tricoli, P. Harmonics and Interharmonics Compensation with Active Front-End Converters Based Only on Local Voltage Measurements. IEEE Trans. Ind. Electron. 2017, 64, 796-805. [CrossRef]

18. Alfonso-Gil, J.; Perez, E.; Arino, C.; Beltran, H. Optimization Algorithm for Selective Compensation in a Shunt Active Power Filter. IEEE Trans. Ind. Electron. 2015, 62, 3351-3361. [CrossRef]

19. Seguí-Chilet, S.; Gimeno-Sales, F.J.; Orts, S.; Alcañiz, M.; Masot, R. Selective Shunt Active Power Compensator in Four Wire Electrical Systems Using Symmetrical Components. Electr. Power Compon. Syst. 2007, 35, 97-118. [CrossRef]

20. Muñoz-Galeano, N.; Alfonso-Gil, J.C.; Orts-Grau, S.; Seguí-Chilet, S.; Gimeno-Sales, F.J. Instantaneous approach to IEEE Std. 1459 power terms and quality indices. Electr. Power Syst. Res. 2015, 125, 228-234. [CrossRef]

21. Alfonso-Gil, J.C.; Vague-Cardona, J.J.; Orts-Grau, S.; Gimeno-Sales, F.J.; Segui-Chilet, S. Enhanced Grid Fundamental Positive-Sequence Digital Synchronization Structure. IEEE Trans. Power Deliv. 2013, 28, 226-234. [CrossRef]

22. Orts-Grau, S.; Gimeno-Sales, F.J.; Abellan-Garcia, A.; Segui-Chilet, S.; Alfonso-Gil, J.C. Improved Shunt Active Power Compensator for IEEE Standard 1459 Compliance. IEEE Trans. Power Deliv. 2010, 25, 2692-2701. [CrossRef]

23. IEEE Standard Definitions for the Measurement of Electric Power Quantities Under Sinusoidal, Nonsinusoidal, Balanced, or Unbalanced Conditions; IEEE Std. 1459-2000; IEEE: New York, NY, USA, 2010.

24. Orts, S.; Gimeno-Sales, F.J.; Abellan, A.; Segui-Chilet, S.; Alcaniz, M.; Masot, R. Achieving Maximum Efficiency in Three-Phase Systems With a Shunt Active Power Compensator Based on IEEE Std. 1459. IEEE Trans. Power Deliv. 2008, 23, 812-822. [CrossRef]

25. Orts-Grau, S.; Munoz-Galeano, N.; Alfonso-Gil, J.C.; Gimeno-Sales, F.J.; Segui-Chilet, S. Discussion on Useless Active and Reactive Powers Contained in the IEEE Standard 1459. IEEE Trans. Power Deliv. 2011, 26, 640-649. [CrossRef]

(c) 2017 by the authors. Licensee MDPI, Basel, Switzerland. This article is an open access article distributed under the terms and conditions of the Creative Commons Attribution (CC BY) license (http://creativecommons.org/licenses/by/4.0/). 